\title{
TERRISCOPE: AN OPTICAL REMOTE SENSING RESEARCH PLATFORM USING AIRCRAFT AND UAS FOR THE CHARACTERIZATION OF CONTINENTAL SURFACES
}

\author{
Y. Boucher ${ }^{1, *}$, A. Amiez ${ }^{2}$, P. Barillot ${ }^{3}$, C. Chatelard ${ }^{3}$, C. Coudrain ${ }^{4}$, P. Déliot ${ }^{1}$, N. Rivière ${ }^{1}$, T. Rivière ${ }^{1}$, L. Roupioz ${ }^{1}$ \\ ${ }^{1}$ ONERA / DOTA, Université de Toulouse, F-31055 Toulouse - France - Yannick.Boucher@ onera.fr \\ ${ }^{2}$ ONERA / DTIS, Université de Toulouse, F-31055 Toulouse - France \\ ${ }^{3}$ ONERA / DOTA, F-13661 Salon cedex Air - France \\ ${ }^{4}$ DOTA, ONERA, Université Paris - Saclay, F-91123 Palaiseau - France
}

KEY WORDS: optical remote sensing; hyperspectral; multispectral; airborne laser scanner; infrared; UAS

\begin{abstract}
:
ONERA is developing TERRISCOPE, a new platform to characterize the environment and the continental surfaces by optical remote sensing using manned aircrafts and UAS (Unmanned Airborne System). The objective of TERRISCOPE is to make available to the scientific community combinations of optical measurements remotely sensed with the best level state-of-the-art sensors. Different kinds of sensors have already been acquired or are still being acquired: Hyperspectral sensors $(0.5-2.5 \mu \mathrm{m}$ range), visible high resolution cameras, multispectral infrared cameras and airborne laser scanners. Each sensor is declined in two versions: one high performance for manned aircrafts and one more compact for UAS. This paper describes the whole equipment, and presents the main characteristics and performances of the carriers, the sensors and the processing chain. Possible sensors combinations on airplanes and UAS are also presented, as well as preliminary results.
\end{abstract}

\section{INTRODUCTION}

Research in environment and continental surfaces characterization is one of the main applications of optical airborne remote sensing. As optical sensors technology has made great progress in the recent years, ONERA is developing a new multi-sensors airborne platform called TERRISCOPE, for research in optical remote sensing. The aim of this platform is to allow one to access various high performance optical sensors through the organization of cooperative airborne campaigns.

This paper presents the TERRISCOPE airborne optical remote sensing platform and reports the progress of its development. It started in January 2016, with the financial support of the European Union (European Regional Development fund), the French Region Occitanie and ONERA. Four private companies also support the project with in-kind investments. Thus, the project team has specified the different facilities, bought some on the shelf or made specific development in some cases. The last steps, still in progress, consist in validating the facilities and integrating the sensors on the aircrafts.

The needs which motivated this development are briefly presented in Section 2, as well as the objectives of the platform. Section 3 presents the carriers, manned aircraft and UAS, and Section 4 the different optical sensors which have been acquired. Section 5 shows the different combinations of sensors that will be available on airplanes and UAS, and reports the progress of their integration. The processing chain, still under development is described Section 6. Few preliminary results are presented Section 7.

\section{OBJECTIVES OF TERRISCOPE PLATFORM}

The development of the TERRISCOPE platform is motivated by a twofold observation: on one hand, many needs remain in the characterization of the environment and of the continental surfaces, and on the other hand optical sensors technology has made great progress in the recent years.

\subsection{Needs}

A need analysis has been performed in the years 2014-2015 about optical characterization of the biosphere, and it appears that optical airborne remote sensing of the continental surfaces is still highly relevant. Indeed, it is complementary to satellite remote sensing and ground measurements, with at the same time high spatial resolution and large field of view. The needs concern the characterization of a wide variety of surfaces: vegetation (species, stress or diseases), bare soils (contents, surface humidity, roughness, pollution...), continental waters and coastal areas, urban and industrial areas. To fulfil these needs, several types of optical sensor have been prioritised: $3 \mathrm{D}$ Lidar, hyperspectral camera in the $0.4-2.5 \mu \mathrm{m}$ range, multispectral infrared camera, and high resolution multispectral visible camera.

\subsection{Objectives}

The first objective of the TERRISCOPE platform consists in giving access to high performance optical sensors, through the organisation of collaborative campaigns of airborne measurements. This will enable to fulfil the needs described above, by providing high quality data sets from a combination of airborne optical sensors. This implies to master the

\footnotetext{
* Corresponding author
} 
calibration of the sensors as well as the quality of the data delivered at different levels by the processing chain.

The second objective of the TERRISCOPE platform aims to promote the development of forthcoming services from UAS, as requested by our main sponsor. This might be done thanks to "proof of concept" campaigns and studies, in cooperation with private companies.

\section{CARRIERS}

\subsection{Manned airplanes}

The manned airplanes used for operating the TERRISCOPE sensors are not part of the platform; they are supplied by ONERA and ONERA's partners.

The most used airplanes are the ATR42 and the Piper-Aztec 23 of SAFIRE (see Figure 1). SAFIRE is the French leading facility for airborne research, a public research infrastructure of the National Centre for Scientific Research (CNRS), the French meteorological service (Météo-France) and the French space agency (CNES). SAFIRE has unique expertise to support environmental and climatic science missions, satellite validation as well as R\&D in aeronautics (SAFIRE, 2017). The ATR42 is pressurized, has a capacity of $2500 \mathrm{~kg}$ for scientific payload, and has two larges rectangular apertures and three round ones under the fuselage. The PA23 is unpressurized, has a payload capacity of around $200 \mathrm{~kg}$, and 3 hatches of different size for down looking.

ONERA provides the Stemme S10-VT motoglider called BUSARD platform (see Figure 1). It's equipped with two pods with a payload capacity of $50 \mathrm{~kg}$ each.

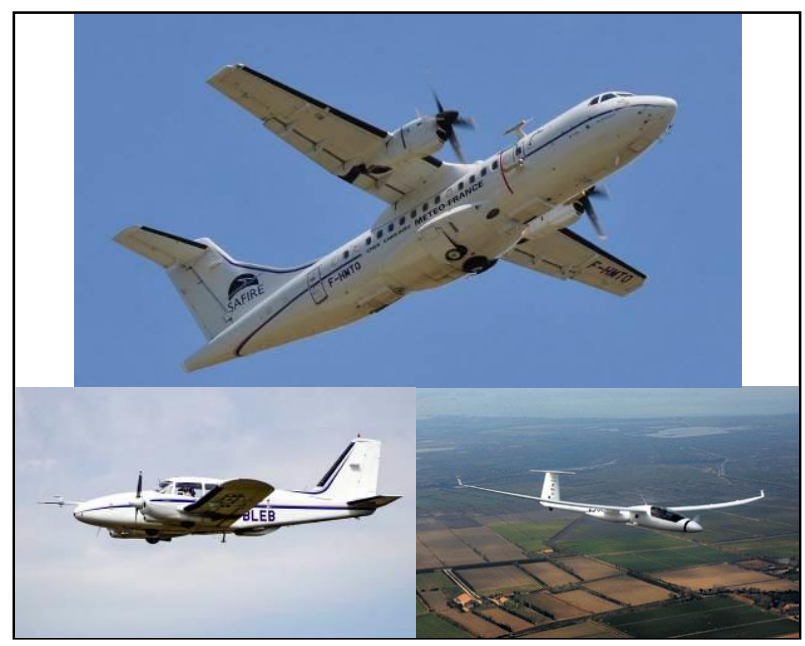

Figure 1. The ATR42 (top, (C DR Safire - J-C. Canonici), PA23 (bottom left, (C DR Safire/Météo-France - JM Destruel) and the Stemme S10-VT of ONERA (bottom right)

\subsection{UAS}

We chose to acquire fixed-wings UAS. Indeed, this kind of UAS is more suitable than rotary wing UAS to perform airborne measurements over wide areas for surfaces characterization, and long duration flights. Thus, two different types of fixed-wings UAS have been acquired within the TERRISCOPE project: one airplane with a MTOW (Maximum Take-Off Weight) less than $125 \mathrm{~kg}$, and four airplanes with a MTOW less than $25 \mathrm{~kg}$. The regulations applying to the first type are very restrictive, but such system has a very interesting payload capacity. The regulations applying to the second type are much lighter, and such system is a good trade-off between payload capacity, long duration flights and operability.

The UAS of the first type is the K75-TITAN of Elecnor Deimos, which actually has an $80 \mathrm{~kg}$ MTOW and a payload capacity of around $35 \mathrm{~kg}$. The platform has a wing span of 4 meters, a length of 3 meters, a cruise speed of $80 \mathrm{~km} / \mathrm{h}$, and autonomy of around 10 hours. The avionics system is an ONERA / DTIS development, which will allow studies and researches on autonomous flights and safety. One example is cited in (Watanabe, 2013). The K75-Titan delivered to ONERA (Figure 2) in April 2018 is the first in the series, and will be commercialized by Elecnor Deimos under the name D80-Titan.

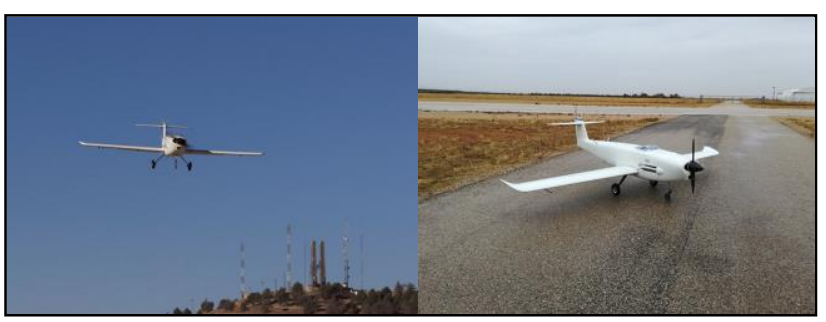

Figure 2. The K75-Titan at Elecnor Deimos facilities in Spain

The UAS of the second type are four BOREAL. The BOREAL UAS has a $25 \mathrm{~kg}$ MTOW and a payload capacity of $7 \mathrm{~kg}$. It has a wing span of 4.2 meters, a length of 1.5 meters, a cruise speed of $100 \mathrm{~km} / \mathrm{h}$, and an autonomy of about 8 hours. Two of these BOREAL UAS are being upgraded to a payload capacity of $10 \mathrm{~kg}$, which constitute the in-kind contribution of Boreal to TERRISCOPE project. The BOREAL UAS is presented Figure 3.

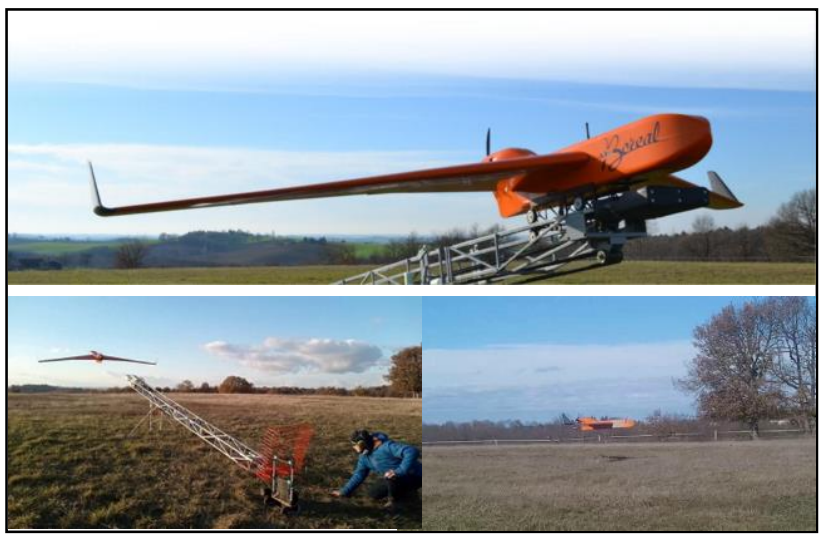

Figure 3. The BOREAL UAS on its catapult (top) and during take-off (bottom left) and landing (bottom right)

\section{OPTICAL SENSORS FOR AIRPLANES AND UAS}

For both manned and unmanned aircrafts, different kinds of sensors have been bought: $0.4-2.5 \mu \mathrm{m}$ hyperspectral cameras, visible multispectral cameras, long-wave infrared cameras and 3D airborne laser scanners. A wind Lidar for the measurement of wind field between the airplane and the ground is also developed by ONERA within the frame of the project, but is out of the scope of this paper. Every sensor (except the wind Lidar) is declined in two versions: one for manned aircraft and one for 
UAS. Both are at the best level of the state of the art. Radiometric and spectral calibration systems for the cameras have also been acquired, like a blackbody and an integrating sphere.

\subsection{Hyperspectral cameras}

The hyperspectral camera for manned airplane, an AISA Fenix $1 \mathrm{k}$ from SPECIM (Figure 4), has already been integrated on an aircraft and first measurements have been done. This camera covers the 0.4 to $2.5 \mu \mathrm{m}$ range, with 348 bands in the $0.4-0.97$ $\mu \mathrm{m}$ range (spectral sampling: $1.7 \mathrm{~nm}$; spectral resolution: 4.5 $\mathrm{nm}$ ), and 256 bands in the $0.97-2.5 \mu \mathrm{m}$ range (spectral sampling: $6.3 \mathrm{~nm}$; spectral resolution: $14 \mu \mathrm{m}$ ). This push-broom sensor has a cross-track field of view of $40^{\circ}$, and the same ground sampling distance (GSD) over the whole spectral range. For example, the GSD is $70 \mathrm{~cm}$ with the aircraft flying at 1100 $\mathrm{m}$ above ground level (AGL). The AISA Fenix 1k has been delivered in August 2017.

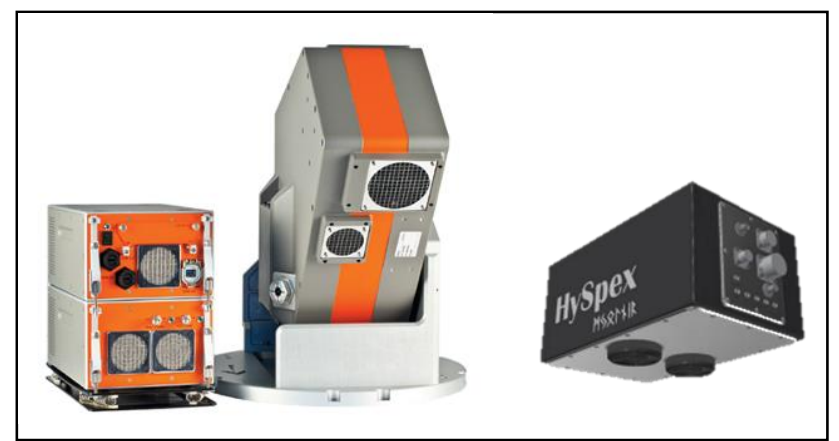

Figure 4. Hyperspectral camera AISA Fenix 1k for airplane (left) and Hyspex Mjolnir FR (right)

The hyperspectral camera for UAS is a Hyspex Mjolnir FR (Figure 4), a specific development from North Electro-Optik (NEO), combining Hyspex Mjolnir V-1240 (VNIR sensor) and Mjolnir s-620 (SWIR sensor) in the same packaging but with two separate entrance pupils. Thus, the VNIR and SWIR sensors don't have same ground sampling distance: $8 \mathrm{~cm}$ for the VNIR@150 m AGL, $22 \mathrm{~cm}$ for the SWIR @150m AGL. The spectral resolution is $4 \mathrm{~nm}$ in the VNIR and $6 \mathrm{~nm}$ in the SWIR. This camera is also a push-broom system. It is relatively compact and light: $38 \times 18 \times 18 \mathrm{~cm}^{3}$ for $6.5 \mathrm{~kg}$. The power consumption is around $50 \mathrm{~W}$. The complete system should have been delivered to ONERA end of September 2018.

\subsection{Multispectral high resolution visible camera}

The idea is to have an easily reconfigurable system of very high spatial resolution visible cameras. Equipped with spectral filters, this system of cameras is able to fulfil the needs for bare soils or vegetation characterization at high spatial resolution, and can be an alternative to hyperspectral cameras. The cameras can also be set up with different viewing angles to measure the multidirectional reflectance of ground surface or to reconstruct the 3D shape of surface and buildings by oblique imagery. Such a multispectral system is currently under development by IGN ${ }^{1}$ (Martin, 2018), based on the ultra-light photogrammetric camera CamLight (Martin, 2014). On the other hand, several very compact multispectral visible cameras for UAV are available on the market: AirPhen from Hi-Phen, RedEdge from

\footnotetext{
${ }^{1}$ Institut National de l'Information Géographique et Forestière
}

Mica Sense, Multispec NDVI-PRI from Arinov, DragonflEYE L6 from Cubert, Parrot Sequoia from Parrot, Tetracam $\mu$-MCA from Tetracam... However, these cameras are based on small and cheap focal planes, so that their spatial resolution is not better than the one of a hyperspectral camera like Hyspex Mjolnir. Since IGN CamLight is not for sale and the small multispectral systems for UAV don't fit our needs, we published in May 2018 a call for tender for a system of 6 cameras (for UAV) or 12 cameras (for manned airplane) with higher specifications. The aimed spatial resolution is less than 5 $\mathrm{cm}$ for UAS @ $150 \mathrm{~m} \mathrm{AGL}$, and less than $25 \mathrm{~cm}$ for airplane @ $1200 \mathrm{~m}$ AGL. The focal plane has to have more than 19 Mpixels. Only one system fits these specifications, and discussions are still ongoing with the supplier. If we can reach an agreement, the delivery is expected before mid-2019.

\subsection{Infrared cameras}

The longwave infrared multispectral camera for manned airplane is a TELOPS MS-IR VLW (Figure 5). This camera is based on a $\mathrm{HgCdTe}$ focal plane of 320 x 256 pixels and a turning filter wheel. The 8 filters are centred on $8.52 \mu \mathrm{m}, 9.13$ $\mu \mathrm{m}, 10.70 \mu \mathrm{m}$ and $11.45 \mu \mathrm{m}$, with a band width of 0.08 to 0.11 $\mu \mathrm{m}$ (full width at half maximum). The GSD will be $37 \mathrm{~cm}$ @ 1200 m AGL.

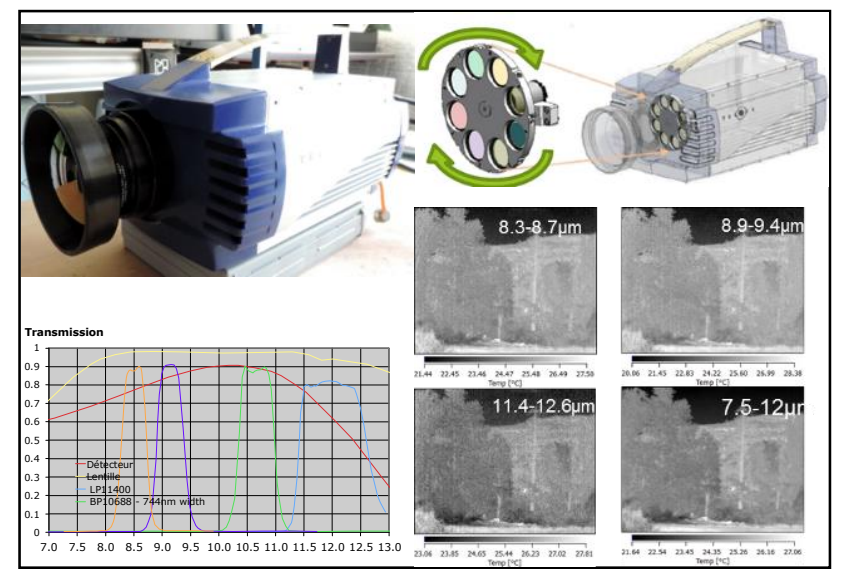

Figure 5. Infrared camera for airplane TELOPS MS-IR VLW (top left and right), filters transmission (bottom left), and ground images in the 4 spectral bands (bottom right)

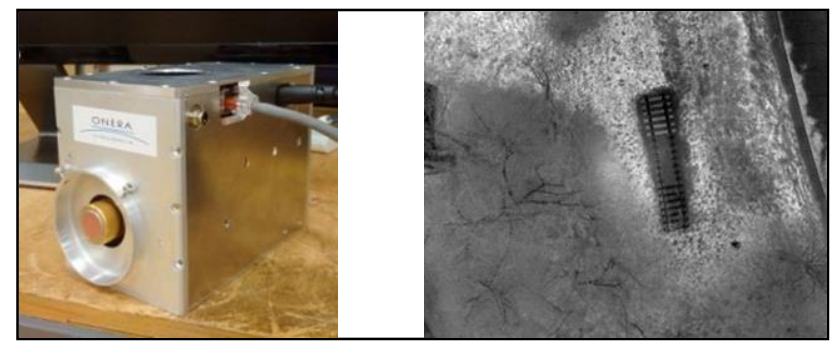

Figure 6. Infrared camera for UAS SOIE (left), and airborne image of a piece of railroad from a rotating wings UAS (right)

Three infrared cameras will be used on UAS. First one, SOIE is a 3-5 $\mu \mathrm{m}$ cryogenic camera, jointly developed by SOFRADIR and ONERA, which constitutes a part of the in-kind investment of SOFRADIR in TERRISCOPE. The cold meniscus of the camera has been replaced by a plano-convex Fresnel lens, decreasing the optical thermal mass of $66 \%$ (Druart, 2016). A 
control-command module has been developed by ONERA. SOIE camera has a volume of $200 \mathrm{~cm}^{3}$ and a mass of $1.5 \mathrm{~kg}$. It has already flown on a rotating wings UAS (Figure 6), and is currently being integrating on BOREAL UAS.

Second one, BIRD is a bi-spectral $(3-5 \mu \mathrm{m}$ and $8-12 \mu \mathrm{m})$ $\mathrm{HgCdTe}$ infrared focal plane from SOFRADIR and constitutes the second part of SOFRADIR in-kind investment. The controlcommand module of this camera is under development by the ONERA team. The integration of this camera on a UAS is planned for 2019.

Last, the MULTICAM camera is a four-band longwave infrared uncooled camera developed by ONERA. Each focal plane has $600 \times 400$ pixels. The 4 cameras are integrated in one system, and the control-command module development is in progress. The GSD will be $25 \mathrm{~cm} @ 150 \mathrm{~m}$ AGL.

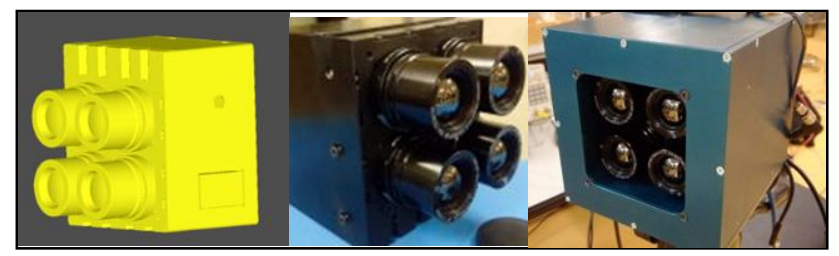

Figure 7. MULTICAM Infrared camera for UAS: from the design to the system

\subsection{Airborne Laser scanners}

The airborne laser scanner for the manned airplane is a RIEGL VQ1560i. This is a 3D fullwave Lidar, with a double scan technology, able to measure 1.33 million points per second with an accuracy of $20 \mathrm{~mm}$ in each direction. It is calibrated in reflectance. The maximum altitude of measurement is around $3800 \mathrm{~m}$ AGL. The number of measured points per square meter depends on flight conditions and Lidar configuration. For instance, $12 \mathrm{pt} / \mathrm{m}^{2}$ can be measured at $60 \mathrm{~m} / \mathrm{s}$ and $1100 \mathrm{~m}$ AGL. The RIEGL VQ1560i has been delivered in January 2018. The system is completed with a very performing inertial measurement unit, and a visible camera. It's being integrating with a GSM4000 stabilised platform on SAFIRE ATR42.

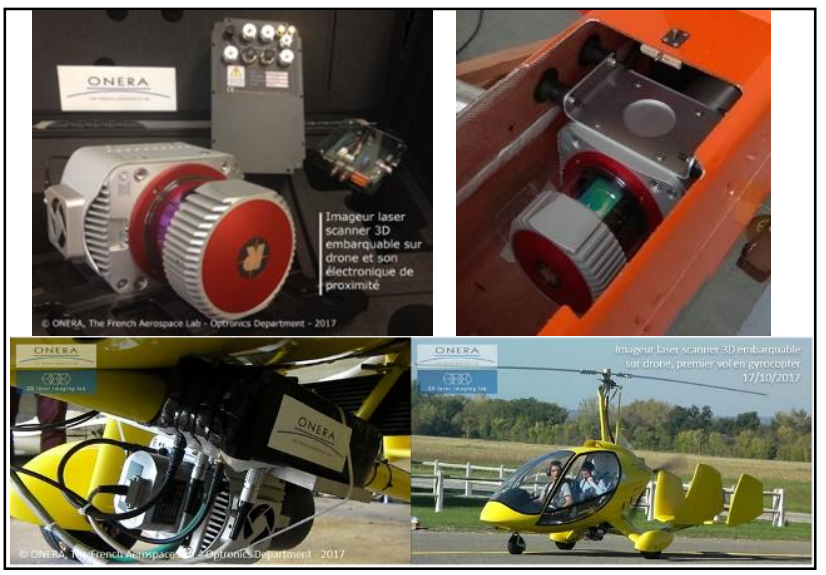

Figure 8. Airborne Laser Scanner RIEGL VUX-SYS-LR for UAS; integration on BOREAL UAS (top right) and on gyrocopter (bottom)

The airborne laser scanner for UAS is a RIEGL VUX-SYS-LR. It combines high performances and compactness $(5.35 \mathrm{~kg})$. The power consumption is around $95 \mathrm{~W}$. It is able to measure 750,000 points per second, the accuracy is $15 \mathrm{~mm}$ in each direction and it is calibrated in reflectance. The maximum altitude of measurement is around $800 \mathrm{~m}$ AGL. The number of measured points per square meter also depends on flight conditions and Lidar configuration. For instance, $20 \mathrm{pt} / \mathrm{m}^{2}$ can be measured at $28 \mathrm{~m} / \mathrm{s}$ and $150 \mathrm{~m}$ AGL The system has been delivered in October 2017, and has already being integrated on a gyrocopter and on the BOREAL UAV (Figure 8).

\section{SENSORS INTEGRATION AND COMBINATIONS}

\subsection{Sensors integration and combination on manned} airplanes

The hyperspectral camera AISA Fenix $1 \mathrm{k}$, the multispectral infrared camera TELOPS MS-IR VLW and the airborne laser scanner RIEGL VQ1560i are presently being integrated on the SAFIRE ATR42. To have a complete modularity in the combination of sensors, the design of mechanical interfaces allows the installation of each sensor independently or jointly with other ones (Figure 9). The RIEGL VQ1560i is positioned above the front aperture. The mechanical outgrowth holding the window and the window itself must be replaced so that the window is inclined at $20^{\circ}$ for avoiding the retro-reflection of the laser in the sensor optics. For the same reason, a new BK7 window with a high performance antireflection coating has been purchased. The hyperspectral AISA Fenix $1 \mathrm{k}$ and the multispectral infrared TELOPS MS-IR camera are positioned above the back aperture, with some space saved for the future multispectral visible camera. The mechanical interface has been designed and manufactured, as well as the bottom side of the mechanical outgrowth and the visible $\mathrm{SiO}_{2}$ and IR Ge windows. The first flight of the ATR42 equipped with TERRISCOPE sensors is planned for the end of October 2018.

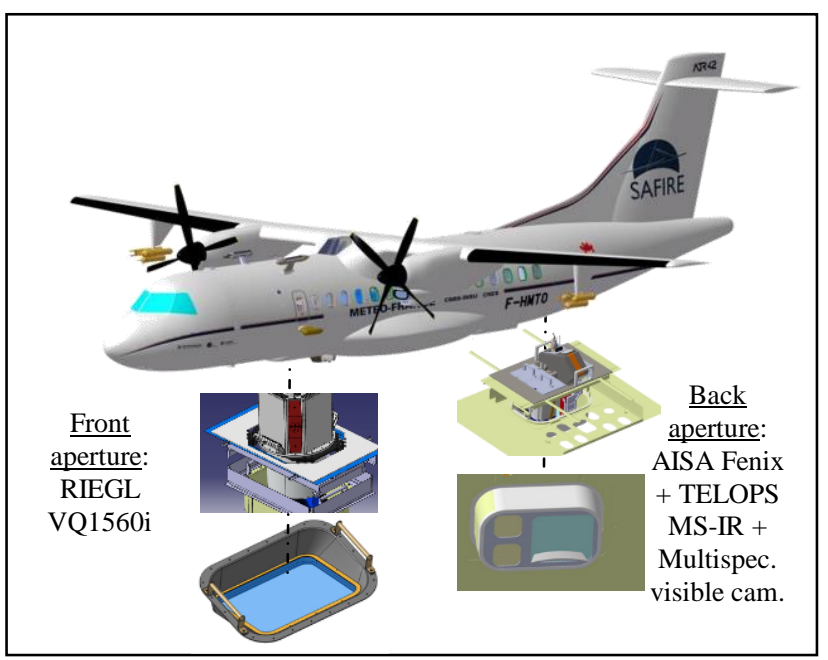

Figure 9. Integration of the sensors in the ATR42

The Piper Aztec PA23 has a load capacity much lower than the ATR42, and neither the AISA Fenix 1k neither the RIEGL VQ can be integrated on this carrier. However, the TELOPS MS-IR has been integrated jointly with a hyperspectral camera and an infrared camera already available at ONERA. A specific mechanical interface has been design for the integration of the TELOPS camera (Figure 10), and a demonstration is also planned end of October 2018. The integration of the TELOPS 
camera on one pod of ONERA's Stemme motoglider is also in progress.

\subsection{Sensors integration and combination on UAS}

All the optical sensors for UAS can be integrated at the same time on the K75-Titan. However, the integration will be carried out in 2019.

As mentioned in Section 4.4, the RIEGL VUX-SYS-LR is already integrated on one BOREAL UAS. The integration of the SOIE infrared camera is in progress, and the integration of the hyperspectral Hyspex Mjolnir FR camera will follow. The plan is that all TERRISCOPE sensors for UAS would be integrated on one BOREAL before mid-2019. Moreover, two of the BOREAL UAS are being upgraded to a payload capacity of 10 $\mathrm{kg}$. Because of the size and the mass of the different sensors, only the following combinations will be possible on one upgraded BOREAL UAS:

- Hyperspectral Hyspex Mjolnir camera + Infrared camera (SOIE or BIRD or MULTICAM)

- $\quad$ RIEGL VUX-SYS-LR Lidar + Infrared camera (SOIE or BIRD or MULTICAM)

- $\quad$ RIEGL VUX-SYS-LR Lidar + multispectral visible camera (to be confirmed)

- Infrared camera (SOIE or BIRD or MULTICAM) + multispectral visible camera

With four BOREAL UAS available, two of which with a bisensors capacity, we will have the capacity to measure with every type of sensors simultaneously (or slightly delayed if the regulations don't allow several BOREAL simultaneous flights).

\section{PROCESSING CHAIN}

The data processing chain has been designed. It is a chain made of various modules for radiometric and geometric corrections, georeferencing and registration of data provided by the different sensors integrated on the same platform. Every type of sensors has its own processing chain and modules, according to Figure 10.

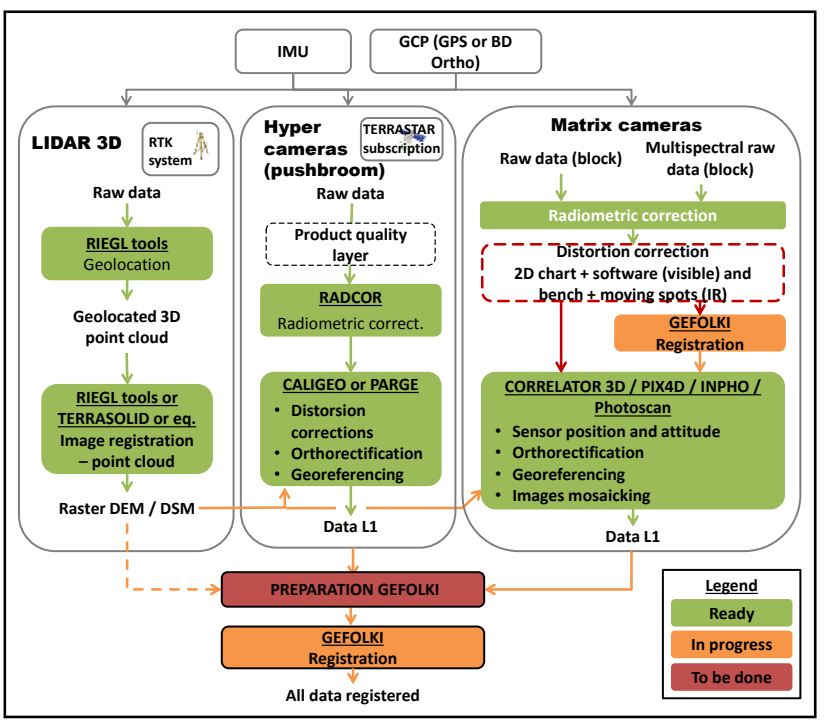

Figure 10. TERRISCOPE processing chain
The tools for georeferencing and post-processing of the point clouds from the Lidars come from RIEGL's proprietary Software package (or equivalent). Georeferencing of hyperspectral data is performed with CALIGEO for AISA Fenix data and with PARGE (Schläpfer, 1998) for HyspexMjolnir data. The registration between the different $\mathrm{L} 1$ data (images, or raster derived from point cloud) will be done with GEFOLKY software, developed by ONERA (Plyer, 2015; Brigot, 2016). The interfaces between the different modules and the graphical user interface are still under development.

\section{PRELIMINARY RESULTS AND PERSPECTIVES}

Some test flights have already been performed with some of the sensors that have been delivered. The hyperspectral AISA Fenix $1 \mathrm{k}$ has been integrated of a Piper PA-31 operated by IMAO, a private French company for aerial data acquisitions. A mosaic of images has been acquired on the ONERA's ground truth base, in the ONERA Fauga-Mauzac Centre near Toulouse (Figure 11).

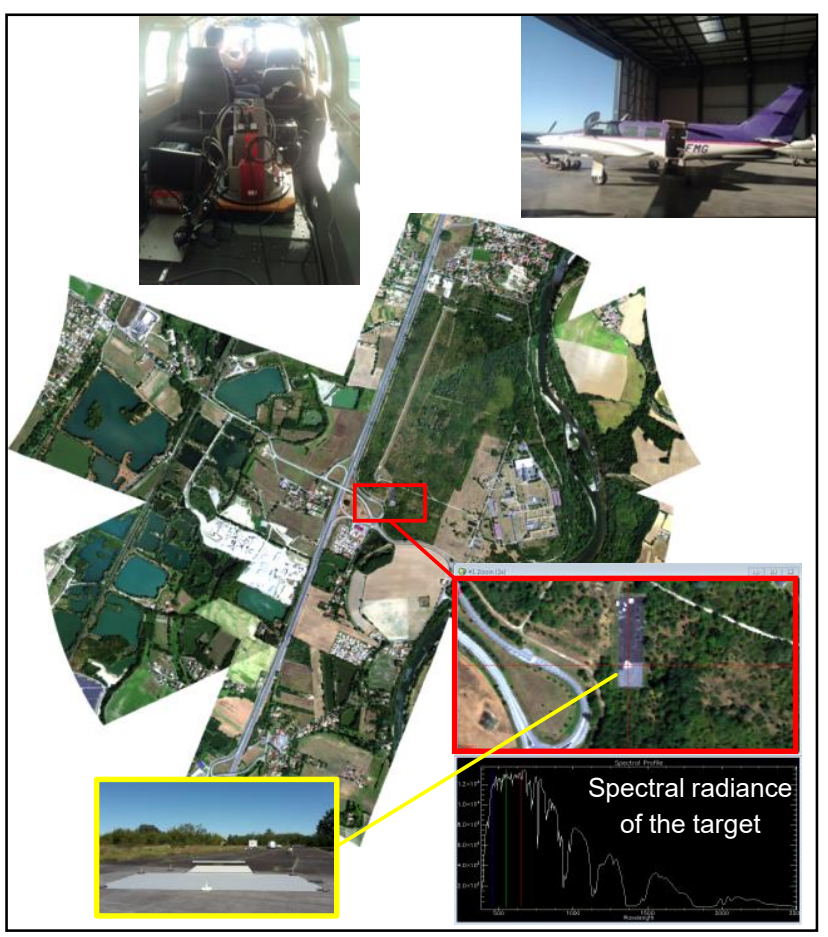

Figure 11. Hyperspectral data acquisition with AISA Fenix 1k on PA-31 of IMAO

As explained in Section 4.4, the RIEGL VUX-SYS-LR airborne laser scanner has been operated on a gyrocopter (Figure 8). Point clouds have been acquired on various landscapes like fields, forest, roads, powerlines... Some examples of the data acquired are presented on Figure 12.

Validation airborne campaigns are planned in October 2018 for aircraft sensors and in November 2018 for airborne laser scanner on UAS. Validation campaigns for the other sensors on UAS will happen at the beginning of 2019, as well as the validation of the data processing chain. Then, the end of the development of the TERRISCOPE platform is planned around mid-2019. 


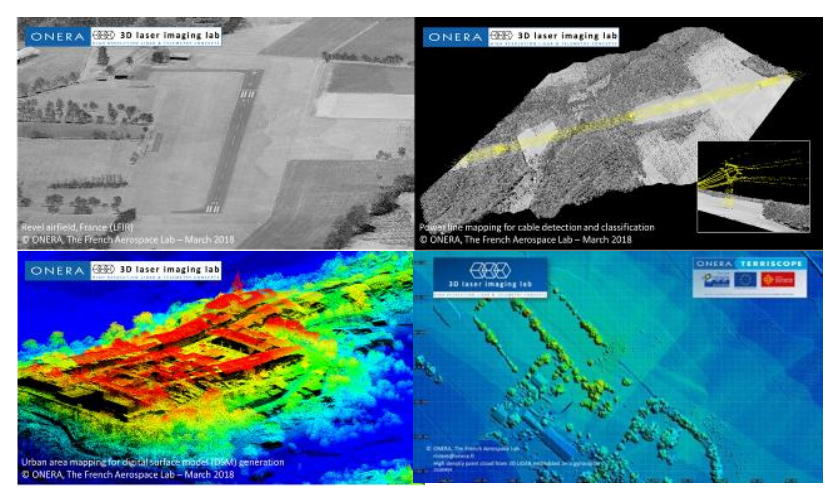

Figure 12. Point clouds measured with the VUX-SYS-LR on gyrocopter: Revel Airfield, France (top left), powerline mapping (top right), urban area mapping (bottom left), and point cloud density in false colours (bottom right)

\section{CONCLUSION}

TERRISCOPE is a new platform of optical remote sensing measurements and imagery from manned airplanes and UAS. It combines different kinds of optical sensors: hyperspectral cameras, multispectral visible and infrared cameras, and airborne lasers scanners. The main sensors and facilities have already been acquired, and are being integrated on the aircrafts. The complete platform will be operational by mid- 2019 .

The TERRICOPE platform provides significant benefits. First, it combines optical sensors at the best level of the state of the art, with a high complementarity, which pave the way for data fusion and advanced processing. Furthermore, the high modularity and the various possible configurations make possible to address a wide variety of needs and applications. The possible applications range from research to industrial applications, with "proof of concept" campaigns and studies. Measurement campaigns can be set-up in a collaborative way for different applications and projects. This open the way to many scientific works using the data, as well as collaboration with other laboratories.

\section{ACKNOWLEDGEMENTS}

TERRISCOPE is developed with the financial support of the European Union (European Regional Development fund), the French Region Occitanie and ONERA. It also received the inkind investment of SOFRADIR, BOREAL, LEOSPHERE and M3 Systems.

\section{REFERENCES}

Brigot, G., Colin-Koeniguer, E., Plyer, A., Janez, F., 2016. Adaptation and Evaluation of an Optical Flow Method Applied to Coregistration of Forest Remote Sensing Images. In: IEEE Journal of Selected Topics in Applied Earth Observations and Remote Sensing, Volume 9, Issue 7, July 2016

Druart, G., Verdet, S., Guerineau, N., Magli, S., Chambon, M., Grulois, T., Matallah, N., 2016. In: Exploring the imaging properties of thin lenses for cryogenic infrared cameras, Proc. SPIE 9822, Advanced Optics for Defense Applications: UV through LWIR, 982214 (17 May 2016);

doi: 10.1117/12.2223588; https://doi.org/10.1117/12.2223588
Martin, O., Meynard, C., Pierrot-Deseilligny, M., Souchon, JP., Thom C., 2014. Réalisation d'une caméra photogrammétrique ultralégère et de haute résolution. Colloque Drones et moyens légers aéroportés d'observation, Montpellier, France, 24-26 Juin 2014.

SAFIRE, 2017. http://www.safire.fr/en/

Martin, O., Meynard, C., Souchon, J-P., Thom C., Le Bris, A., 2018. Caméra SUSPECT (SUper-SPECTrale) du LOEMI : de la suspicion à la mise à l'épreuve. 27es journées de la Recherche IGN, Cité Descartes, Marne-la-Vallée, les 22 et 23 mars 2018.

Plyer, A., Colin-Koeniguer, E., Weissgerber, F., 2015. A New Coregistration Algorithm for Recent Applications on Urban SAR Images. In: Geoscience and Remote Sensing Letters, IEEE, vol.12, no.11, pp. 2198 - 2202, nov 2015

Schläpfer, D., Schaepman M., Itten, K., 1998. PARGE: Parametric geocoding based on GCP-calibrated auxiliary data. IN: Proc. SPIE 3438 Imaging spectrometry IV, San Diego 1998, pp 334-344

Watanabe, Y., Amiez A., Chavent, P., 2013. Fully-autonomous coordinated flight of multiple UAVs using decentralized virtual leader approach. In: IEEE/RSJ International Conference on Intelligent Robots and Systems, Tokyo, 2013, pp. 5736-5741. doi: 10.1109/IROS.2013.6697187 